\title{
Engineering Three-Dimensionally Electrodeposited Si-on-Ni Inverse Opal Structure for High Volumetric Capacity Li-Ion Microbattery Anode
}

\author{
Hao Liu, ${ }^{\dagger}$ Hyung-Man Cho, ${ }^{\ddagger}$ Ying Shirley Meng, ${ }^{*}+\underset{*}{*}$ and Quan $\mathrm{Li}^{*}{ }^{\dagger}$
}

${ }^{\dagger}$ Department of physics, The Chinese University of Hong Kong, Shatin, New Territory, Hong Kong, Hong Kong

${ }^{\ddagger}$ Department of NanoEngineering, University of California, San Diego, 9500 Gilman Drive, La Jolla, California 92093, United States

Supporting Information

ABSTRACT: Aiming at improving the volumetric capacity of nanostructured Li-ion battery anode, an electrodeposited Sion-Ni inverse opal structure has been proposed in the present work. This type of electrode provides three-dimensional bicontinuous pathways for ion/electron transport and high surface area-to-volume ratios, and thus exhibits lower interfacial resistance, but higher effective $\mathrm{Li}$ ions diffusion coefficients, when compared to the Si-on-Ni nanocable array electrode of the same active material mass. As a result, improved volumetric capacities and rate capabilities have been demonstrated in the Si-on-Ni inverse opal anode. We also show that optimization of the volumetric capacities and the rate performance of the inverse opal electrode can be realized by manipulating the pore size of the Ni scaffold and the thickness of the Si deposit.

KEYWORDS: Si anode, inverse opal, electrodeposition, 3D current collector, Li-ion battery, volumetric capacity
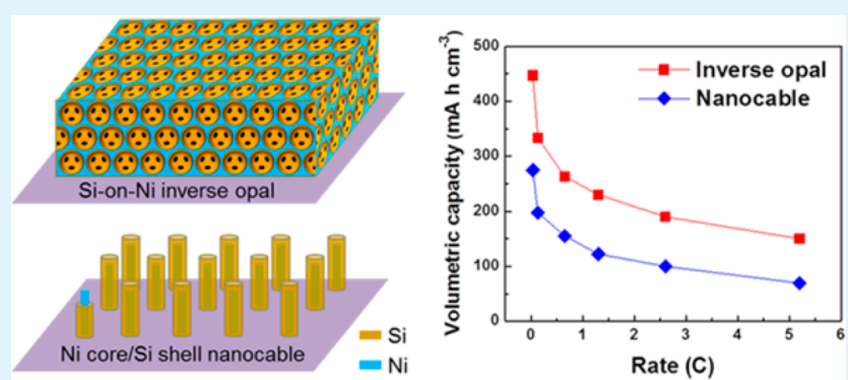

Rate (C)

\section{INTRODUCTION}

Integrated microelectronics devices such as microsensors, ${ }^{1}$ biological micromonitors, ${ }^{2}$ or microelectronic pills ${ }^{3}$ have been widely used for ambient sensors, smart medicines, etc. To meet the size requirement of the microelectronics devices, the integrated power sources must have a small footprint area (e.g., $\left.<1 \mathrm{~cm}^{2}\right)^{4}$ and volume but relatively high energy density to supply a desirable electric power. Traditional thin film microbatteries with two-dimensional (2D) geometries cannot satisfy both size and energy requirements simultaneously. ${ }^{5}$ Compared to 2D configurations, three-dimensionally (3D) nanostructured configurations exhibits several unique advantages for the application in the microelectronics devices, due to their (1) higher surface area-to-volume ratios, which can increase the mass loading of active materials per unit footprint area and (2) abundant interspaces, which help to accommodate the volumetric change of active materials during the lithiation/ delithiation process. $\$, 6$

In fact, a 3D Si-on-Ni nanocable array has been demonstrated as a Li-ion battery (LIB) anode, which shows high specific capacities and good cycling retention abilities. ${ }^{7}$ However, the volumetric capacities of the nanocable composited electrodes were low due to the relatively low mass loading of the active material on the metallic nanowire current collector. Exploring possible improvements on the volumetric capacity by designing suitable nanostructured electrodes, we investigated a different type of 3D nanostructured configuration, a Si-on-Ni inverse opal structure, 
(a)

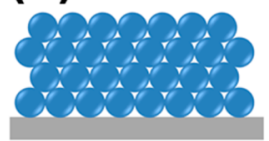

(I)

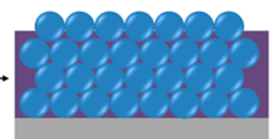

! (II)

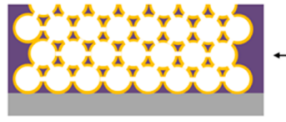

(IV)

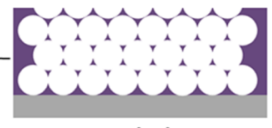

(III)
Nickel substrate $\odot$ PS $=$ Nickel scaffold $=$ Silicon
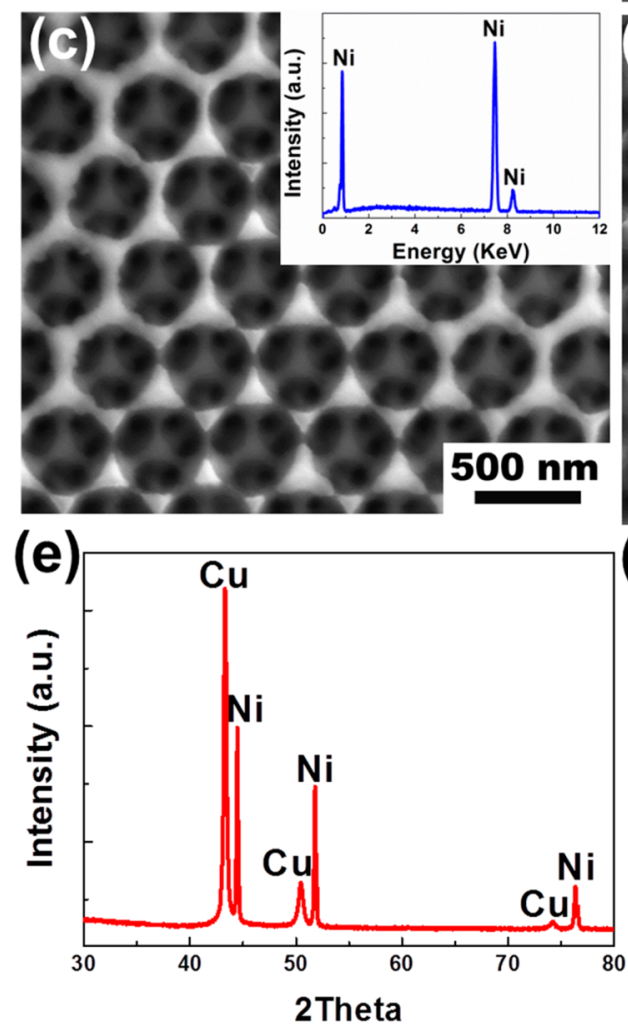
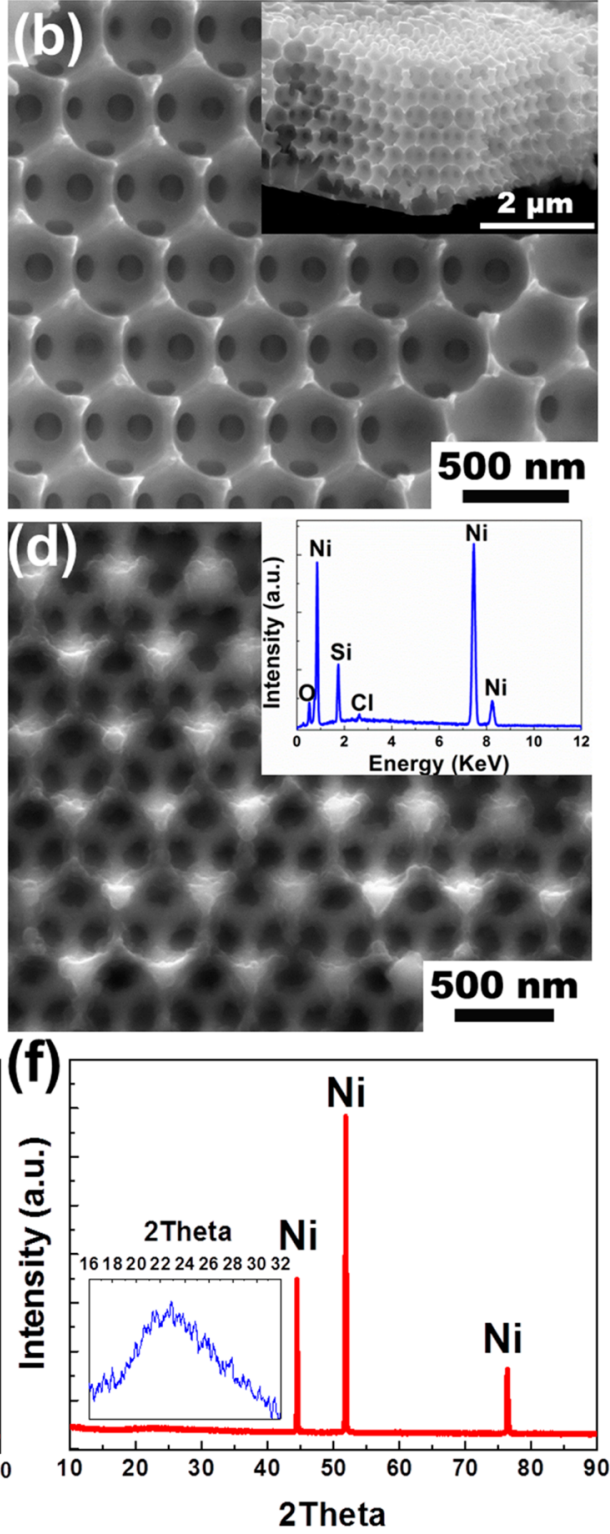

Figure 1. (a) Schematics of the synthetic process of the Si-on-Ni inverse opal electrode. Top view SEM images of the (b) as-deposited (side-view shown in the inset); (c) electropolished Ni inverse opal (EDX of the sample shown in the inset); (d) Si deposited on Ni inverse opal scaffold (EDX of the sample shown in the inset). (e) XRD $\theta-2 \theta$ scan of the electropolished $\mathrm{Ni}$ inverse opal scaffold on Cu substrate. (f) XRD $\theta-2 \theta$ scan of the Si deposited on $\mathrm{Ni}$ inverse opal scaffold (Ni substrate). The magnified $2 \theta$ region from $16^{\circ}$ to $32^{\circ}$ is shown in the inset.

performance and volumetric capacities can be engineered by controlling the pore sizes of metallic $\mathrm{Ni}$ scaffolds and the thickness of the Si deposit.

\section{RESULTS AND DISCUSSION}

Figure 1a illustrates the synthetic process of the Si-on-Ni inverse opal electrode. The morphology of the as-synthesized $\mathrm{Ni}$ inverse opal structure is shown in Figure $1 \mathrm{~b}$. The thickness of the inverse opal can be easily controlled by the electrodeposition duration (kept at $\sim 3 \mu \mathrm{m}$ in the present study). The interconnected pores among the spherical voids in the $\mathrm{Ni}$ inverse opal are shown in Figure 1c. The pore size is enlarged from $\sim 70$ to $\sim 150 \mathrm{~nm}$. Only the Ni signal is detected in the energy-dispersive X-ray spectroscopy (EDX) spectrum (inset of Figure 1c). A thin Si layer is uniformly electrodeposited on the surface of the $\mathrm{Ni}$ inverse opal scaffold from the top to the bottom of the sample (see Figure S1 in the Supporting
Information) with a $1.0 \mathrm{~A} \cdot \mathrm{s}$ electrical charge passed through the electrode (to differentiate the electric charge unit " $C$ " from the charging/discharging rate "C", here we adopted " $A \cdot s$ " for the former. This electrode is named Sample $410 \mathrm{~nm}-1.0 \mathrm{~A} \cdot \mathrm{s})$. The Si shell thickness is $\sim 31 \pm 4 \mathrm{~nm}$ with a mass of $\sim 42 \mu \mathrm{g}$ (the $\mathrm{Si}$ thickness was statistically estimated by counting at least 50 different sample regions in highly magnified SEM images, and then taking their average). The EDX spectrum (inset of Figure 1d) indicates that the shell is mainly composed of $\mathrm{Si}$ with impurities of $\mathrm{O}$ and $\mathrm{Cl}$ (the $\mathrm{Ni}$ signal comes from the $\mathrm{Ni}$ inverse opal scaffold). The crystallinity of both Ni scaffold and the Si-on-Ni inverse opal was examined using X-ray diffraction (XRD). It should be noted that the Ni scaffold sample was grown on $\mathrm{Cu}$ instead of $\mathrm{Ni}$ foil as the substrate. The XRD taken from such a sample is shown in Figure 1e, which discloses diffraction peaks from the Ni (JCPDS No. 4-850) and $\mathrm{Cu}$ (substrate) only. The XRD taken from the Si-on-Ni inverse 

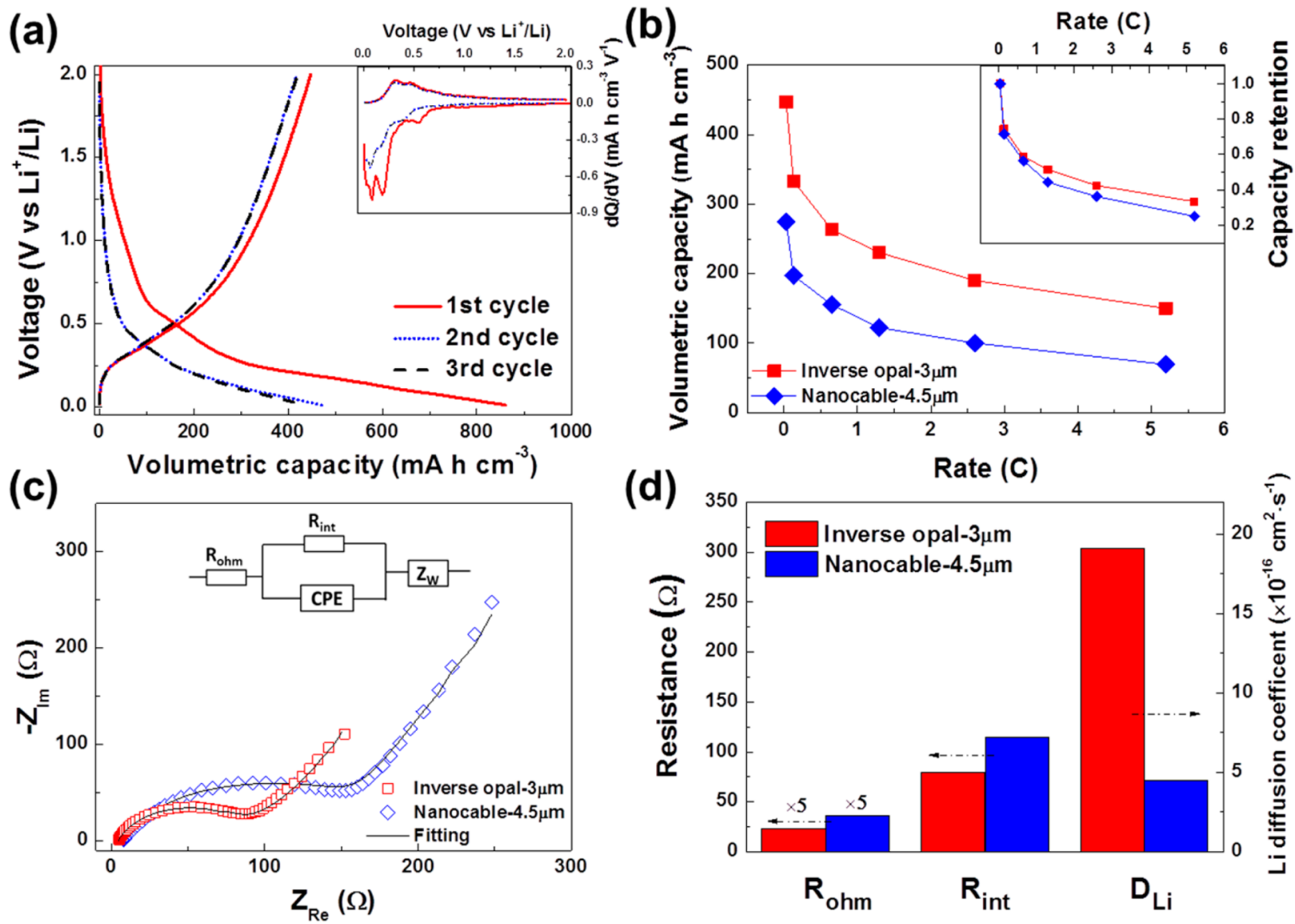

Figure 2. (a) Voltage profiles of Sample $410 \mathrm{~nm}-1.0 \mathrm{~A} \cdot \mathrm{s}$ during the first and second cycles under a $0.03 \mathrm{C}$ rate. The inset shows the differential capacity-voltage curves. (b) Comparison of the volumetric capacities between Sample nanocable- $4.5 \mu \mathrm{m}$, and inverse opal-3 $\mu \mathrm{m}$ at various rates. (c) Nyquist plots of these two electrodes at $2 \mathrm{Vvs} \mathrm{Li}^{+} / \mathrm{Li}$ potential during charging process. The inset shows the equivalent circuit model for the two electrodes. $R_{\text {ohm }}$ stands for series ohmic resistance. $R_{\text {int }}$ and CPE represent interfacial resistance and capacitance, respectively. $Z_{\mathrm{w}}$ represents Warburg impedance. The lines in panel $\mathrm{c}$ are the fitted curves by using this model. (d) Comparison of the individual real impedances, $R_{\mathrm{ohm}}, R_{\mathrm{int}}$ and the effective $\mathrm{Li}$ ion diffusion coefficient $D_{\mathrm{Li}}$ between these two electrodes.

opal sample shows no additional diffraction peaks. Only a weak and broad bump is observed in the $2 \theta$ range of $16^{\circ}-32^{\circ}$ (Figure 1f). This broad bump corresponds to the amorphous $\mathrm{SiO}_{2}$, which froms due to the easy oxidation of the electrodeposited $\mathrm{Si}$ being exposed to air (during XRD measurement). ${ }^{7}$

Figure 2 shows the voltage profiles of Sample $410 \mathrm{~nm}-1.0 \mathrm{~A} \cdot \mathrm{s}$ during the first and second cycles under a $0.03 \mathrm{C}$ rate. The sloping voltage profiles during lithiation (discharge) are consistent with the lithiation behavior of amorphous $\mathrm{Si}^{13,14}$ In the first cycle, discharging and charging volumetric capacities of $\sim 860$ and $\sim 448 \mathrm{~mA} \mathrm{~h} \mathrm{~cm}^{-3}$ are obtained, respectively, with a low coulombic efficiency $(\sim 52 \%)$. The first large irreversible loss is likely contributed by surface film formation, such as the formation of the SEI layer (decomposition of electrolyte) ${ }^{15,16}$ and surface $\mathrm{SiO}_{x}$ (reaction with trace water in the electrolyte). ${ }^{17,18}$ In the subsequence cycling, the coulombic efficiencies are increased to $\sim 89 \%$ and further improved to $>97 \%$ after a few more cycles. To better understand the lithiation and delithiation behavior of the $\mathrm{Si}$-on-Ni inverse opal electrode, the differential capacity-voltage curves (inset of Figure 2a) are derived from the voltage profiles. In the discharging process, the peaks around $0.54 \mathrm{~V}$ relate to the reaction between $\mathrm{Li}$ and $\mathrm{SiO}_{x}$ at the electrode surface. ${ }^{19}$ The other two peaks around 0.19 and $0.09 \mathrm{~V} \mathrm{vs}^{+} / \mathrm{Li}$ correspond to the phase transition from a-Si to a- $\mathrm{Li}_{x} \mathrm{Si}$ and $\mathrm{a}-\mathrm{Li}_{x} \mathrm{Si}$ to a- $\mathrm{Li}{ }_{\sim 2.8} \mathrm{Si}$, respectively. ${ }^{20,21} \mathrm{An}$ additional wide hump is observed between $\sim 1.5$ and $0.8 \mathrm{~V}$ vs $\mathrm{Li}^{+} / \mathrm{Li}$, contributed by the decomposition of the electrolyte to form the SEI layer. ${ }^{22,23}$ During the charging process, $\mathrm{Li}$ is extracted from $\mathrm{Si}$ at $\sim 0.32$ and $\sim 0.46 \mathrm{~V}_{\text {vs }} \mathrm{Li}^{+} / \mathrm{Li}$ through the phase transition from a- $\mathrm{Li}_{\sim 2.8} \mathrm{Si}$ to a- $\mathrm{Li}_{x} \mathrm{Si}$ then to a-Si. However, the lithiation behavior in the second cycle is different from that in the first cycle. In the second cycle, the wide hump between

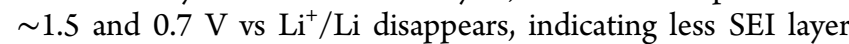
formation during the second discharging process. In addition, the reduction peaks are found to move to $\sim 0.38$ and $\sim 0.07 \mathrm{~V}$ vs $\mathrm{Li}^{+} / \mathrm{Li}$ due to different kinetics of a-Si lithiation in the corresponding cycles. In the first cycle, a-Si lithiation is controlled by the breakup of the strong $\mathrm{Si}-\mathrm{Si}$ bonds, while the following lithiation is dominated by the $\mathrm{Li}$ diffusion. ${ }^{21}$ Nevertheless, the following cycles show fairly similar characteristics to the second cycle, indicating the relatively good reversibility of the Si-on-Ni inverse opal electrode. ${ }^{24}$

The volumetric capacities of Sample $410 \mathrm{~nm}-1.0 \mathrm{~A} \cdot \mathrm{s}$ decrease progressively with increased rates from 0.03 to $5.2 \mathrm{C}(1 \mathrm{C}=$ $4200 \mathrm{~mA} \mathrm{~g}^{-1}$, see Figure S3a in the Supporting Information). At low rate of 0.03 and $0.13 \mathrm{C}$, this electrode exhibits a volumetric capacity of $\sim 420$ and $\sim 330 \mathrm{~mA} \mathrm{~h} \mathrm{~cm}^{-3}$, respectively. At a high rate of $5.2 \mathrm{C}$, the charging volumetric capacity remains at $\sim 150 \mathrm{~mA} \mathrm{~h} \mathrm{~cm}{ }^{-3}$. The decayed capacity is recovered 

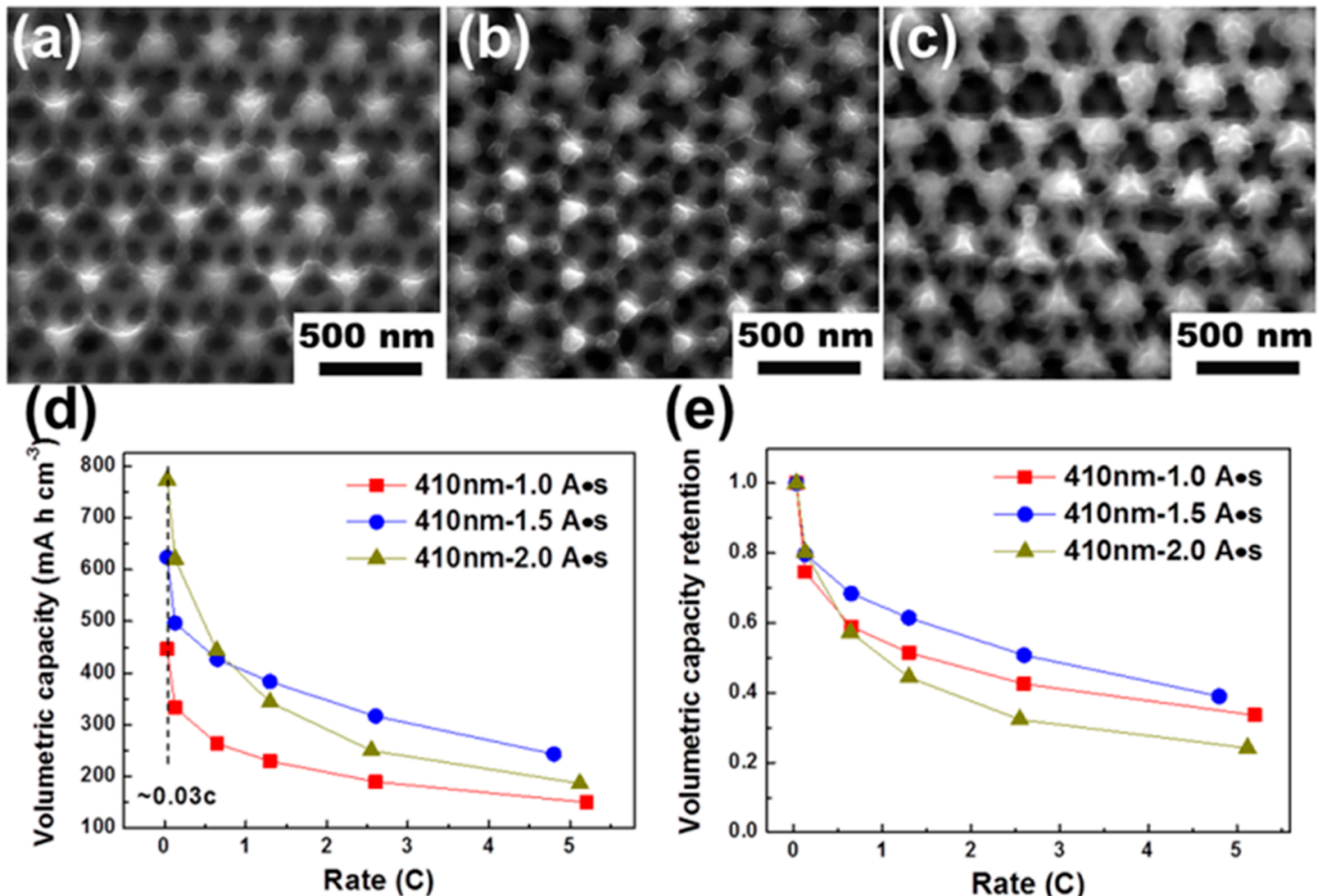

(e)
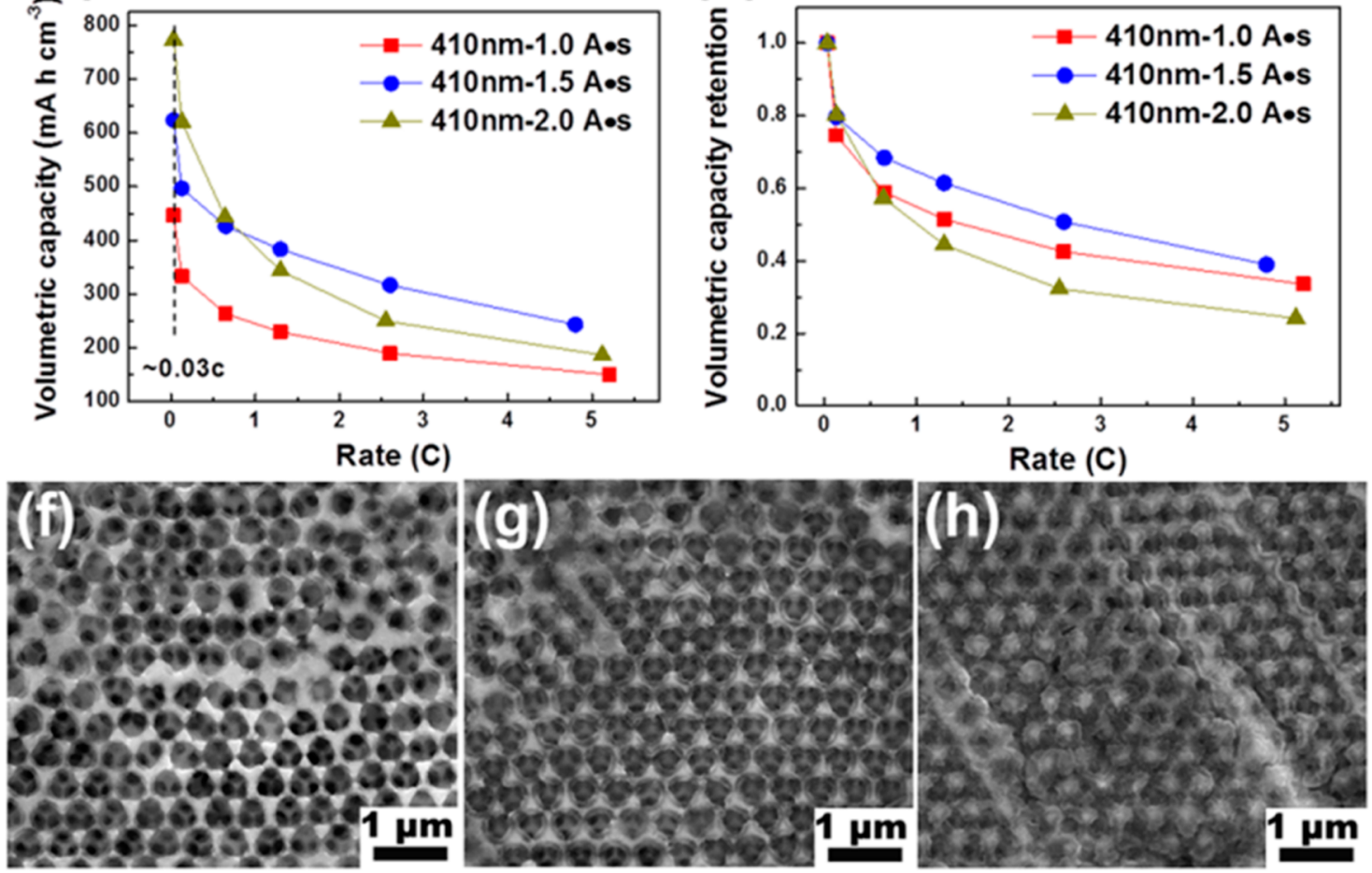

Figure 3. Top-view SEM images of Sample (a) $410 \mathrm{~nm}-1.0 \mathrm{~A} \cdot \mathrm{s}$; (b) $410 \mathrm{~nm}-1.5 \mathrm{~A} \cdot \mathrm{s}$; (c) $410 \mathrm{~nm}-2.0 \mathrm{~A} \cdot \mathrm{s}$. (d) Comparison of the volumetric capacities of Sample $410 \mathrm{~nm}-1.0,1.5$, and 2.0 A.s. (e) The corresponding capacity retention of the three inverse opal electrodes. Top-view SEM images of Sample (f) $410 \mathrm{~nm}-1.0 \mathrm{~A} \cdot \mathrm{s} ;(\mathrm{g}) 410 \mathrm{~nm}-1.5 \mathrm{~A} \cdot \mathrm{s} ;$ (h) $410 \mathrm{~nm}-2.0$ A.s taken after discharge at $0.65 \mathrm{C}$ rate.

to $\sim 254 \mathrm{~mA} \mathrm{~h} \mathrm{~cm}{ }^{-3}$ when the rate goes back to $0.13 \mathrm{C}$, indicating its good capacity retention ability. Meanwhile, this electrode also delivers high specific capacities at various rates, e.g., $\sim 3150 \mathrm{~mA} \mathrm{~h} \mathrm{~g}^{-1}$ (in terms of the mass of the Si deposit) at rate of $0.03 \mathrm{C}$ (Figure S3b, Supporting Information).

We compared the electrochemical performance of this Si-on$\mathrm{Ni}$ inverse opal electrode to another representative 3D nanostructured system, i.e., the $\mathrm{Si}$-on-Ni nanocable electrode (see Figure S2 in the Supporting Information) with same Si mass. The substrate foot area of the nanocable and the inverse opal samples were kept the same. We named the two samples using their morphology and total thickness (substrate excluded) characteristics, i.e., nanocable- $4.5 \mu \mathrm{m}$ and inverse opal-3 $\mu \mathrm{m}$. The total surface area in Sample nanocable- $4.5 \mu \mathrm{m}$ is $\sim 20 \mathrm{~cm}^{2}$, which is comparable to that of Sample inverse opal-3 $\mu \mathrm{m}$ (surface area $\sim 21 \mathrm{~cm}^{2}$, see Table $\mathrm{S} 1$ in the Supporting Information). As a result, the two samples have similar thicknesses of the $\mathrm{Si}$ deposit layer, i.e., $\sim 28 \mathrm{~nm}$ in Sample nanocable $-4.5 \mu \mathrm{m}$ and $\sim 31 \mathrm{~nm}$ in Sample inverse opal-3 $\mu \mathrm{m}$. Nevertheless, one should note that the volume of Sample nanocable- $4.5 \mu \mathrm{m}$ is larger than that of Sample inverse opal-3 $\mu \mathrm{m}$, and this should be normalized when comparing their volumetric capacity.

The first charging volumetric capacities are plotted at different rates for these two samples (Figure 2b). It is found that the inverse opal electrode exhibits much higher volumetric capacities than those of the nanocable array electrode at all rates, as well as better rate capability. For example, at a high rate of $4 \mathrm{C}$, the inverse opal electrode retains at $\sim 150 \mathrm{~mA} \mathrm{~h} \mathrm{~cm}^{-3}$, showing a $\sim 117 \%$ improvement when compared to that of Sample nanocable- $4.5 \mu \mathrm{m}\left(\sim 69 \mathrm{~mA} \mathrm{~h} \mathrm{~cm}^{-3}\right)$. Nevertheless, the cyclabilities of these two electrodes are comparable (see Figure S3d in the Supporting Information). It should be noted that both electrodes show continuous capacity fading, which probably results from the continuous growth of the SEI layer on the Si surface, the SEI layer takes forever to stabilize when new surfaces keep on forming as $\mathrm{Si}$ undergoes volume change. ${ }^{25}$ Nevertheless, the formation of the SEI layer would be mitigated if an appropriate electrolyte, e.g., ionic liquid type of electrolyte, and/or proper surface coating are chosen.

Generally speaking, the potential and current distributions in an electrochemical cell greatly depend on the geometries, e.g., 


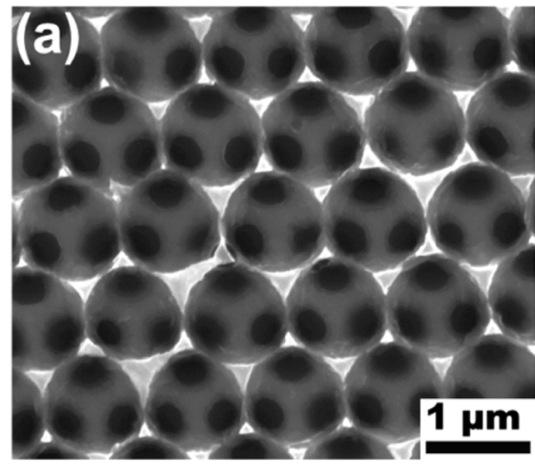

(d)

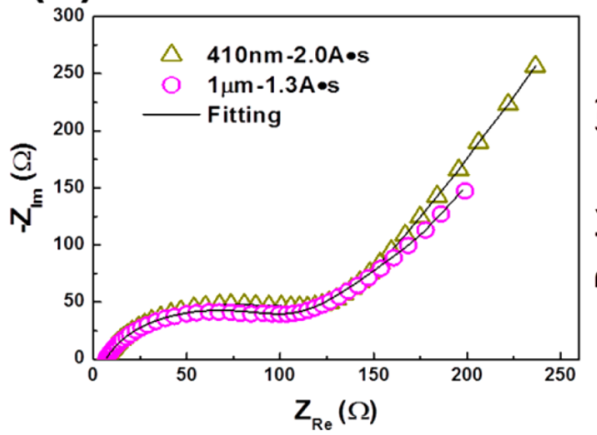

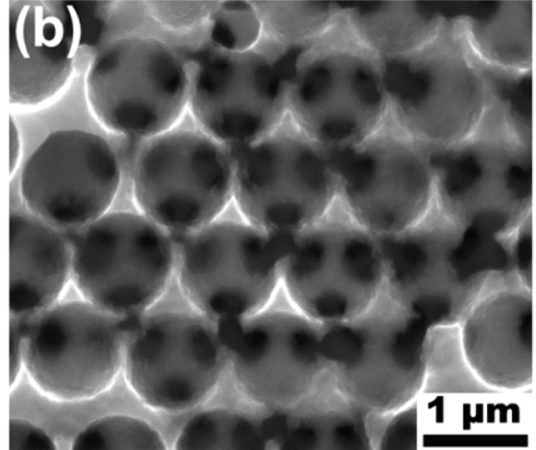

(e)

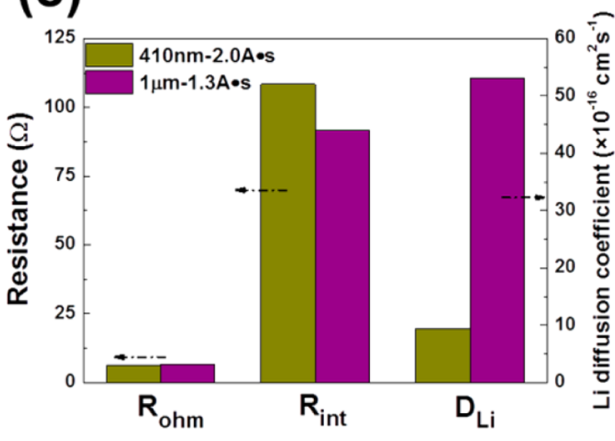

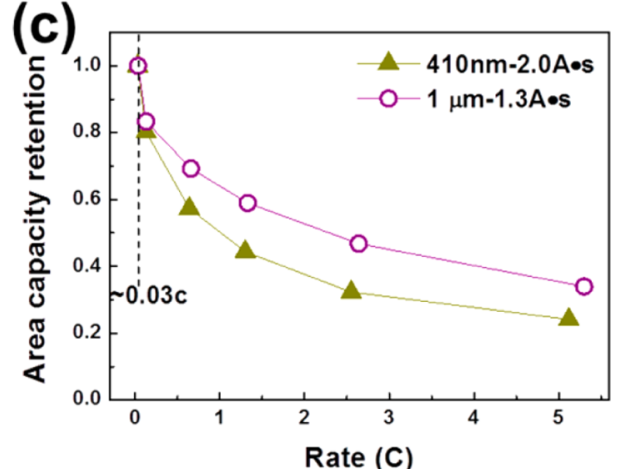

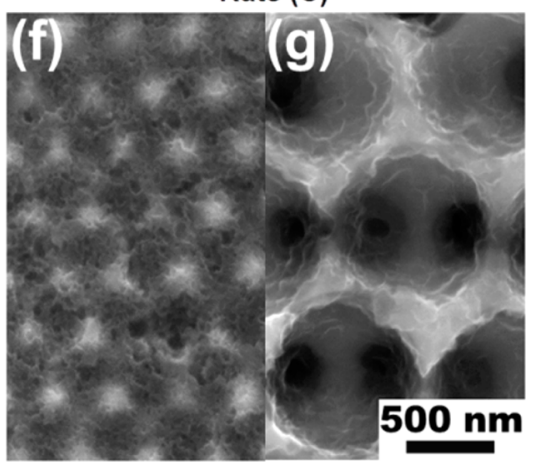

Figure 4. Top-view SEM images of (a) electropolished Ni inverse opal derived from $1 \mu \mathrm{m}$ PS template; (b) Si-on-Ni (thickness 50 nm) inverse opal (Sample $1 \mu \mathrm{m}-1.3 \mathrm{~A} \cdot \mathrm{s}$ ). (c) Comparison of volumetric capacity retention of Sample $410 \mathrm{~nm}-2.0 \mathrm{~A} \cdot \mathrm{s}$ and Sample $1 \mu \mathrm{m}-1.3 \mathrm{~A} \cdot \mathrm{s}$. (d) Nyquist plots of these two corresponding inverse opal electrodes at the potential $2 \mathrm{~V}$ vs $\mathrm{Li}^{+} / \mathrm{Li}$ during charge. The lines are the fitted curves by using the previous equivalent circuit model. (e) Comparison of the individual real impedance, $R_{\mathrm{ohm}}$, $R_{\mathrm{int}}$, and the effective $D_{\mathrm{Li}}$ between those two inverse opal electrodes. Top-view SEM images of Sample (f) $410 \mathrm{~nm}-2.0 \mathrm{~A} \cdot \mathrm{s}$; (g) $1 \mu \mathrm{m}-1.3 \mathrm{~A} \cdot \mathrm{s}$ taken after discharging for $12 \mathrm{~h}$.

porosity and surface roughness, of the electrodes. If the electrodes are rough and/or the bulk properties of the material are inhomogeneous, both the potential and current distributions will be different in the respective electrodes, leading to different charge transport properties such as different interfacial charge transfer and ion diffusion processes. ${ }^{26,27}$ To gain a better understanding on the difference between the inverse opal and the nanocable electrodes, electrochemical impedance spectroscopy (EIS) measurements were carried out at the potential of 2 $\mathrm{V} v \mathrm{Li}^{+} / \mathrm{Li}$ and the Nyquist plots are shown in Figure $2 \mathrm{c}$. The intercept of the real axis at high frequency is dominated by series ohmic resistance, which contributed by external cell connections and ionic conduction through the electrolyte and separator. A semicircle at the high-to-medium frequency region represents interfacial resistance resulting from charge transfer resistance on the electrode interface and the presence of a passivating SEI layer. The followed inclined line at the low frequency region relates to $\mathrm{Li}$ ion diffusion in the solid-state electrode. $^{28}$ An appropriate equivalent circuit model (inset of Figure 2c) was established to fit the Nyquist curves. The electrical parameters, e.g., $R_{\mathrm{ohm}}$ and $R_{\text {int }}$ in this model can be calculated (see Table $S 2$ in the Supporting Information), as shown in Figure 2d. The interfacial resistance of Sample inverse opal-3 $\mu \mathrm{m}$ is smaller than that of Sample nanocable- $4.5 \mu \mathrm{m}$, although their surface areas are similar. This is ascribed to the different configurations of these two types of nanostructured electrodes. In the nanocable configuration, each individual nanowire provides only 1D charge transport pathways. In contrast, the bi-continuous 3D inverse opal configuration can supply more ionic/electrical transport pathways, which will facilitate the charge transport. ${ }^{29}$ Therefore, the polarization can be reduced in the inverse opal electrode, allowing higher capacities to be realized.

To better understand the $\mathrm{Li}$ ion diffusion characteristics of the inverse opal electrode and the nanocable electrode, the effective $\mathrm{Li}$ ion diffusion coefficient $D_{\mathrm{Li}}$ are estimated from EIS, ${ }^{30}$ according to the equation

$$
D_{\mathrm{Li}}=\frac{1}{2}\left[\frac{V_{\mathrm{m}}}{S F \sigma}\left(-\frac{\mathrm{d} E}{\mathrm{~d} x}\right)\right]^{2}
$$

in which $V_{\mathrm{m}}$ is the mole volume of $\mathrm{Si}$; $S$ is the surface area of electrode (calculated based on face-center cubic structure of inverse opal electrode); $F$ is the Faraday constant; $\sigma$ is the Warburg factor, which can be obtained from the fitting at low frequency in EIS; $\mathrm{d} E / \mathrm{d} x$ can be estimated from the slope of galvanostatic charge-discharge profiles. The results of $\sigma, \mathrm{d} E /$ $\mathrm{d} x \mathrm{l}$, and $D_{\mathrm{Li}}$ are summarized in Table S2 (Supporting Information). The effective $\mathrm{Li}$ ion diffusion coefficient of the inverse opal electrode is considerably larger than that of the nanocable electrode (Figure 2d) due to their different configurations (as discussed earlier). It is well-known that the rate capability of LIB is mainly determined by the $\mathrm{Li}$ ion diffusion ability of in the active materials. ${ }^{31}$ Therefore, the inverse opal electrode shows better rate performance due to its higher effective $\mathrm{Li}$ ion diffusion coefficient.

To increase the volumetric capacities of the Si-on-Ni inverse opal electrode, more active material ( $\mathrm{Si}$ in the present case) was deposited onto the $\mathrm{Ni}$ inverse opal current collector. The quantities of charge passed through the electrodes during the electrodeposition were 1.5 A.s and 2.0 A.s (Sample $410 \mathrm{~nm}-1.5$ and $410 \mathrm{~nm}-2.0 \mathrm{~A} \cdot \mathrm{s})$, corresponding to $\sim 40 \pm 5$ and $\sim 50 \pm 6$ $\mathrm{nm}$ Si shell thicknesses (Figure 3b,c), respectively. Figure 3d 
shows the comparison of the volumetric capacities of the three inverse opal electrodes (Sample $410 \mathrm{~nm}-1.0 \mathrm{~A} \cdot \mathrm{s}, 410 \mathrm{~nm}-1.5 \mathrm{~A}$. $\mathrm{s}$, and $410 \mathrm{~nm}-2.0 \mathrm{~A} \cdot \mathrm{s})$. When the $\mathrm{Si}$ shell thickness increased from $\sim 31 \mathrm{~nm}$ (Sample $410 \mathrm{~nm}-1.0 \mathrm{~A} \cdot \mathrm{s}$ ) to $\sim 40 \mathrm{~nm}$ (Sample $410 \mathrm{~nm}-1.5 \mathrm{~A} \cdot \mathrm{s})$, the volumetric capacities are improved at all rates (corresponding specific capacities are shown in Figure S3c in the Supporting Information). When the Si shell thickness further increased to $\sim 50 \mathrm{~nm}$ (Sample $410 \mathrm{~nm}-2.0 \mathrm{~A} \cdot \mathrm{s}$ ), the volumetric capacity is further increased at relatively low rates $(<0.65 \mathrm{C})$. For example, the volumetric capacity of Sample 410 $\mathrm{nm}-2.0 \mathrm{~A} \cdot \mathrm{s}$ exhibits $\sim 700 \mathrm{~mA} \mathrm{~h} \mathrm{~cm}{ }^{-3}$ at a rate of $0.07 \mathrm{C}(294$ $\mathrm{mA} \mathrm{g}^{-1}$ ), which is $\sim 1.6$ to $\sim 6$ times higher than that of other typical binder-free Si-based electrodes. ${ }^{32,33}$ On the other hand, the volumetric capacities of Sample $410 \mathrm{~nm}-2.0$ A.s rapidly decrease with the rate increase and become even lower than those of $\sim 40 \mathrm{~nm}$ Si shell samples at $\sim 0.65$ to $5 \mathrm{C}$ (Figure $3 \mathrm{~d}$ ). This is to say, Sample $410 \mathrm{~nm}-2.0 \mathrm{~A} \cdot \mathrm{s}$ with $\sim 50 \mathrm{~nm} \mathrm{Si}$ shell exhibits the worst capacity retention ability (Figure $3 \mathrm{e}$ ).

To identify the cause of the decreased capacity retention when the deposited Si thickness increases to $\sim 50 \mathrm{~nm}$ (in Sample $410 \mathrm{~nm}-2.0 \mathrm{~A} \cdot \mathrm{s}$ ), the corresponding coin-cells were disassembled and characterized after discharge (lithiation) at a $0.65 \mathrm{C}$ rate. After lithiation, the Si layer thicknesses expanded to $39 \pm 7,52 \pm 6$, and $78 \pm 12 \mathrm{~nm}$ (Figure $3 \mathrm{f}-\mathrm{h}$ ), corresponding to Sample $410 \mathrm{~nm}-1.0,1.5$, and $2.0 \mathrm{~A} \cdot \mathrm{s}$. On the one hand, the $\mathrm{Li}$ ion diffusion becomes more difficult due to the $\mathrm{Si}$ layer thickness increase from Sample $410 \mathrm{~nm}-1.0$ to Sample $410 \mathrm{~nm}$ $2.0 \mathrm{~A} \cdot \mathrm{s}$. On the other hand, the volume fraction of the liquid electrolyte in the inside pores of the inverse opal electrodes drops due to the expansion of lithiated Si layer, causing less adequate contact between the electrode material and the electrolyte. In particular, when the thickness of the Si layer expands to $\sim 78 \mathrm{~nm}$, most pores are found to be filled by a solid substance and only very limited interspaces are left to accommodate the liquid electrolyte. Because the $\mathrm{Li}$ ion transport in liquid electrolyte is faster than that in solid-state $\mathrm{Si}$ or $\mathrm{Si}-\mathrm{Li}$ alloy, blocking the electrolyte flow slows down $\mathrm{Li}$ transport during the cycling process. Both factors can be responsible for the worst capacity retention observed in Sample $410 \mathrm{~nm}-2.0 \mathrm{~A} \cdot \mathrm{s}$.

To find out which one of them serves as the limiting factor, another Si-on-Ni inverse opal electrode was designed. In this sample, the deposited Si layer thickness $(\sim 50 \mathrm{~nm})$ was kept the same as that of Sample $410 \mathrm{~nm}-2.0 \mathrm{~A} \cdot \mathrm{s}$. Nevertheless, the pore sizes of the $\mathrm{Ni}$ inverse opal scaffold were increased by employing $1 \mu \mathrm{m}$ PS template (Sample $1 \mu \mathrm{m}-1.3 \mathrm{~A} \cdot \mathrm{s}$ ) during the $\mathrm{Ni}$ scaffold fabrication. As shown in Figure $4 \mathrm{a}$, the interconnected pore size of the $\mathrm{Ni}$ inverse opal scaffold is enlarged to $\sim 300 \mathrm{~nm}$. It should be noted that the mass of the active material is different in these two inverse opal electrodes (Sample $410 \mathrm{~nm}-2.0 \mathrm{~A} \cdot \mathrm{s}, \sim 66 \mu \mathrm{g}$; Sample $1 \mu \mathrm{m}-1.3 \mathrm{~A} \cdot \mathrm{s}, ~ 43$ $\mu \mathrm{g})$. Therefore, the lower capacity of Sample $1 \mu \mathrm{m}-1.3 \mathrm{~A} \cdot \mathrm{s}$ is due to its smaller surface area to accommodate the $\mathrm{Si}$ deposit. Nevertheless, in this set of experiments, we only need to compare the charging volumetric capacity retention of Sample $410 \mathrm{~nm}-2.0 \mathrm{~A} \cdot \mathrm{s}$ and Sample $1 \mu \mathrm{m}-1.3 \mathrm{~A} \cdot \mathrm{s}$, which is evaluated from the decaying trend of the electrode volumetric capacity when the charging rate is increased. It clearly shows that Sample $1 \mu \mathrm{m}-1.3$ A.s exhibits better rate performance (Figure 4 c). For example, it delivers $\sim 60 \%$ of its initial volumetric capacity at rate of $1.3 \mathrm{C}$, while at the same rate, only $\sim 44 \%$ of initial volumetric capacity is retained for Sample $410 \mathrm{~nm}-2.0 \mathrm{~A}$.

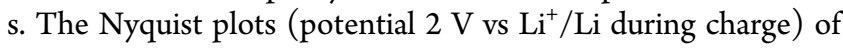

these two corresponding inverse opal electrodes are shown in Figure $4 \mathrm{~d}$. Using the previous equivalent circuit model, the individual resistances $R_{\mathrm{ohm}}, R_{\mathrm{int}}$, and effective diffusion coefficient $D_{\mathrm{Li}}$ of these two inverse opal electrodes can be obtained, as shown in Figure $4 \mathrm{e}$ (or see Table S2 in the Supporting Information). These results indicate that the series ohmic resistance and the interfacial resistance of these two electrodes are quite similar. In contrast, the effective $\mathrm{Li}$ ion diffusion coefficient of Sample $1 \mu \mathrm{m}-1.3 \mathrm{~A} \cdot \mathrm{s}$ is nearly 6 times higher than that of Sample $410 \mathrm{~nm}-2.0$ A.s. Because the Si layer thicknesses of these two inverse opal electrodes are similar during the cycling (both initial Si shell thickness $\sim 50 \mathrm{~nm}$; lithiated shell thickness $\sim 78 \mathrm{~nm}$ for Sample $410 \mathrm{~nm}-2.0$ A.s and $\sim 70 \mathrm{~nm}$ for Sample $1 \mu \mathrm{m}-1.3 \mathrm{~A} \cdot \mathrm{s})$, the pore size in the inverse opal structure is suggested to serve as the major reason for the observed difference in the two electrodes. The open pores serve as the liquid electrolyte channels, resulting in low $\mathrm{Li}$ ion transport resistance. To confirm this hypothesis, the two

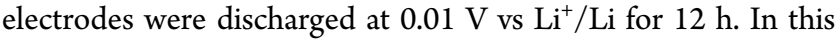
process, as much as possible, $\mathrm{Li}$ ions are inserted into the electrode. As a result, almost all interspaces are filled by the lithiated Si alloy in Sample $410 \mathrm{~nm}-2.0 \mathrm{~A} \cdot \mathrm{s}$ due to the volumetric expansion during discharge (Figure 4f). In contrast, the interconnected pores are still open after lithiation in Sample $1 \mu \mathrm{m}-1.3 \mathrm{~A} \cdot \mathrm{s}$ (Figure $4 \mathrm{~g}$ ), providing adequate channels for the flow of liquid electrolyte. These results indicate that the main limitation for the volumetric capacity retention of Sample 410 $\mathrm{nm}-2.0 \mathrm{~A} \cdot \mathrm{s}$ is the relatively small interconnected pore size rather than the thicker $\mathrm{Si}$ shell. Further increase of the $\mathrm{Si}$ shell thickness to $65 \pm 6 \mathrm{~nm}$ on the $1 \mu \mathrm{m}$ pore size Ni scaffold (Sample $1 \mu \mathrm{m}-2.0 \mathrm{~A} \cdot \mathrm{s}$, see Figure S4a in the Supporting Information) leads to an improved volumetric capacity at low cycling rates but a decreased volumetric retention ability as compared to Sample $1 \mu \mathrm{m}-1.3 \mathrm{~A} \cdot \mathrm{s}$ (see Figure S4c and S4d in the Supporting Information). As the interconnected pores are still open in Sample $1 \mu \mathrm{m}-2.0$ A.s (see Figure S4b in the Supporting Information), the worsened rate performance is likely due to the longer ionic/electric transport pathways in thicker Si shells. The results also suggest that the volumetric capacity retention ability can be manipulated by adjusting the pore size of the Ni inverse opal scaffold and the thickness of the Si deposit.

\section{CONCLUSIONS}

In summary, the 3D metallic $\mathrm{Si}$-on-Ni inverse opal anode was fabricated by electrodeposition. When compared to the nanocable array electrode counterpart of the same active material mass, the composite inverse opal electrode demonstrated considerable improvement in the volumetric capacities and rate capabilities. This is ascribed to the $3 \mathrm{D}$ bi-continuous transport pathways provided by the inverse opal nanoarchitecture for ion/electron transport and high surface areato-volume ratio, resulting in lower interfacial resistance but a higher effective $\mathrm{Li}$ ion diffusion coefficient during the discharging/charging process. Optimization of the rate performance and volumetric capacities of the inverse opal electrode can be realized by manipulating the pore size of the $\mathrm{Ni}$ inverse opal scaffold and the thickness of the Si deposit. The $\mathrm{Si}$-on-Ni inverse opal electrode derived from $410 \mathrm{~nm}$ PS template with $\sim 40 \mathrm{~nm} \mathrm{Si} \mathrm{deposit} \mathrm{was} \mathrm{identified} \mathrm{to} \mathrm{have} \mathrm{the} \mathrm{best}$ performance, i.e., highest rate capabilities and high volumetric capacities are simultaneously achieved. 


\section{METHODS}

Electrodeposition of the Si-on-Ni Inverse Opal Electrode. The synthetic process of the $\mathrm{Si}$-on-Ni inverse opal electrode is summarized in Figure 1a. First, a 3D colloidal crystal template was grown on a $\mathrm{Ni}$ foil substrate by electrophoretic deposition. ${ }^{34} \mathrm{~A}$ mixture containing $0.5 \mathrm{~mL}$ aqueous suspension of colloidal polystyrene microsphere (PS, diameter $410 \mathrm{~nm}$ or $1 \mu \mathrm{m}, 4 \% \mathrm{w} / \mathrm{v}$, life technologies Co.), $73 \mu \mathrm{L}$ aqueous ammonium (30\%), and $2.5 \mathrm{~mL}$ of ethanol was used as an electrolyte. During the deposition, a Pt foil was used as the cathode and a constant voltage of $3 \mathrm{~V}$ was applied to the $\mathrm{Ni}$ foil anode. After deposition, the coated $\mathrm{Ni}$ foil was dried in air.

Secondly, Ni metal was electrodeposited into the interspace of that PS template. In this step, the coated $\mathrm{Ni}$ foil was immersed into a water-ethanol mixture $(4: 1, \mathrm{v} / \mathrm{v})$ solution containing $1 \mathrm{M} \mathrm{NiSO}_{4}$. $6 \mathrm{H}_{2} \mathrm{O}$ and $0.3 \mathrm{M} \mathrm{H}_{3} \mathrm{BO}_{3}$. A constant cathodic current $\left(-2 \mathrm{~mA} \mathrm{~cm}^{-2}\right)$ was used for $\mathrm{Ni}$ electrodeposition. After that, the PS template was burnt out in air $\left(300{ }^{\circ} \mathrm{C}\right.$ for $\left.1 \mathrm{~h}\right)$, and then the inverse opal scaffold was reduced in $10 \% \mathrm{H}_{2} / \mathrm{Ar}$ gas $\left(400{ }^{\circ} \mathrm{C}\right.$ for $\left.1 \mathrm{~h}\right)$. To increase the internal pore size of the $\mathrm{Ni}$ inverse opal, the sample was electropolished at room temperature.

Finally, a Si layer was deposited on the $\mathrm{Ni}$ inverse opal through electrodeposition as described previously. ${ }^{7}$ After $\mathrm{Si}$ deposition, a brownish yellow deposited layer was observed. The mass of the $\mathrm{Si}$ was indirectly determined after its being completely oxidized to $\mathrm{SiO}_{2}$.

Characterizations. The crystallinity of the samples was examined by $\mathrm{X}$-ray diffraction (XRD, SmartLab, Rigaku) with $\mathrm{Cu} \mathrm{K} \alpha$ radiation source $(d=0.1541 \mathrm{~nm})$. The morphologies and the chemical composition were characterized by a field emission scan electron microscope (FESEM, Quanta 200, FEI), equipped with an energydispersive X-ray detector (EDX, Oxford). Transmission electron microscopy (TEM) was also carried out for the microstructural investigation of the samples using a Tecnai F20 microscope operating at $200 \mathrm{kV}$.

Electrochemical Properties of the Si-on-Ni Inverse Opal Electrode. The electrochemical properties of the samples were examined using CR2032 coin-type cells with $\mathrm{Li}$ foil as counter electrode. The liquid electrolyte was $1.0 \mathrm{M} \mathrm{LiPF}_{6}$ in ethylene carbonate/diethyl carbonate solvent $(1: 1 \mathrm{v} / \mathrm{v}$, Novolyte Co.). After the cells assembled in an argon-filled glove box $\left(\mathrm{H}_{2} \mathrm{O}<0.1 \mathrm{ppm}, \mathrm{O}_{2}<0.1\right.$ ppm, M. Braun Inertgas Systems Co., Ltd.), the electrochemical testing was performed between 0.02 and $2.0 \mathrm{~V}$ using LAND batteries testing system (CT2001A, Wuhan Kingnuo Electronic Co., Ltd.). The electrochemical impedance spectroscopy (EIS) of the batteries was tested in the frequency range from $100 \mathrm{kHz}$ to $1 \mathrm{~Hz}$ under an alternating current (AC) stimulus with a $10 \mathrm{mV}$ of amplitude (CHI 660C, Shanghai Chenhua Instrument Co., Ltd.). After cycling test, the coin-cells were disassembled to characterize the morphologies change of the electrode. The solid-electrolyte interphase (SEI) layer on the electrode surface was removed by dilute acetic acid. ${ }^{35}$

\section{ASSOCIATED CONTENT}

\section{S Supporting Information}

Calculation of surface area of the metallic nanowire array and inverse opal structure, characterization of Sample $410 \mathrm{~nm}-1.0$ A.s, morphology of the Si-on-Ni nanocable array, volumetric and specific capacities of Sample $410 \mathrm{~nm}-1.0 \mathrm{~A} \cdot \mathrm{s}$ and $410 \mathrm{~nm}-$ 1.5 A.s at various rates, comparison of cycling performance of the inverse opal and nanocable electrodes, and the summarized $R_{\mathrm{ohm}}, R_{\mathrm{int}} \sigma,|\mathrm{d} E / \mathrm{d} x|$, and $D_{\mathrm{Li}}$ of the inverse opal and nanocable electrodes. This material is available free of charge via the Internet at http://pubs.acs.org.

\section{AUTHOR INFORMATION}

\section{Corresponding Authors}

*Q. Li. E-mail: liquan@phy.cuhk.edu.hk.

*Y. S. Meng. E-mail: shirleymeng@ucsd.edu.

\section{Notes}

The authors declare no competing financial interest.

\section{ACKNOWLEDGMENTS}

This work is supported by General Research funding of the Research Grants Council of Hong Kong under project No. 414612. Y. S. Meng acknowledges the support of American Chemical Society Petroleum Research Fund (51311-DNI10).

\section{REFERENCES}

(1) Humble, P. H.; Harb, J. N. Optimization of Nickel-Zinc Microbatteries for Hybrid Powered Microsensor Systems. J. Electrochem. Soc. 2003, 150, A1182-A1187.

(2) Lemmerhirt, D. F.; Wise, K. D. Chip-Scale Integration of DataGathering Microsystems. Proc. IEEE 2006, 94, 1138-1159.

(3) Johannessen, E. A.; Lei, W.; Li, C.; Tong Boon, T.; Ahmadian, M.; Astaras, A.; Reid, S. W. J.; Yam, P. S.; Murray, A. F.; Flynn, B. W.; Beaumont, S. P.; Cumming, D. R. S.; Cooper, J. M. Implementation of Multichannel Sensors for Remote Biomedical Measurements in a Microsystems Format. IEEE Trans. Biomed. Eng. 2004, 51, 525-535.

(4) Cheah, S. K.; Perre, E.; Rooth, M.; Fondell, M.; Hårsta, A.; Nyholm, L.; Boman, M.; Gustafsson, T. r.; Lu, J.; Simon, P.; Edström, K. Self-Supported Three-Dimensional Nanoelectrodes for Microbattery Applications. Nano Lett. 2009, 9, 3230-3233.

(5) Arthur, T. S.; Bates, D. J.; Cirigliano, N.; Johnson, D. C.; Malati, P.; Mosby, J. M.; Perre, E.; Rawls, M. T.; Prieto, A. L.; Dunn, B. ThreeDimensional Electrodes and Battery Architectures. MRS Bull. 2011, 36, 523-531.

(6) Zhu, J.; Jiang, J.; Feng, Y.; Meng, G.; Ding, H.; Huang, X. ThreeDimensional Ni/SnOx/C Hybrid Nanostructured Arrays for LithiumIon Microbattery Anodes with Enhanced Areal Capacity. ACS Appl. Mater. Interfaces 2013, 5, 2634-2640.

(7) Liu, H.; Hu, L.; Meng, Y. S.; Li, Q. Electrodeposited ThreeDimensional Ni-Si Nanocable Arrays as High Performance Anodes for Lithium Ion Batteries. Nanoscale 2013, 5, 10376-10383.

(8) Zhang, H.; Braun, P. V. Three-Dimensional Metal Scaffold Supported Bicontinuous Silicon Battery Anodes. Nano Lett. 2012, 12, $2778-2783$

(9) Yao, Y.; McDowell, M. T.; Ryu, I.; Wu, H.; Liu, N.; Hu, L.; Nix, W. D.; Cui, Y. Interconnected Silicon Hollow Nanospheres for Lithium-Ion Battery Anodes with Long Cycle Life. Nano Lett. 2011, 11, 2949-2954.

(10) Esmanski, A.; Ozin, G. A. Silicon Inverse-Opal-Based Macroporous Materials as Negative Electrodes for Lithium Ion Batteries. Adv. Funct. Mater. 2009, 19, 1999-2010.

(11) Nicholson, J. P. Electrodeposition of Silicon from Nonaqueous Solvents. J. Electrochem. Soc. 2005, 152, C795-C802.

(12) Nishimura, Y.; Fukunaka, Y. Electrochemical Reduction of Silicon Chloride in a Non-aqueous Solvent. Electrochim. Acta 2007, 53, 111-116.

(13) Li, J. C.; Dozier, A. K.; Li, Y. C.; Yang, F. Q.; Cheng, Y. T. Crack Pattern Formation in Thin Film Lithium-Ion Battery Electrodes. J. Electrochem. Soc. 2011, 158, A689-A694.

(14) Chen, L. B.; Xie, J. Y.; Yu, H. C.; Wang, T. H. An Amorphous Si Thin Film Anode With High Capacity and Long Cycling Life for Lithium Ion Batteries. J. Appl. Electrochem. 2009, 39, 1157-1162.

(15) Chan, C. K.; Ruffo, R.; Hong, S. S.; Cui, Y. Surface Chemistry and Morphology of The Solid Electrolyte Interphase on Silicon Nanowire Lithium-Ion Battery Anodes. J. Power Sources 2009, 189, $1132-1140$.

(16) Nadimpalli, S. P. V.; Sethuraman, V. A.; Dalavi, S.; Lucht, B.; Chon, M. J.; Shenoy, V. B.; Guduru, P. R. Quantifying Capacity Loss Due to Solid-Electrolyte-Interphase Layer Formation on Silicon Negative Electrodes in Lithium-Ion Batteries. J. Power Sources 2012, $215,145-151$.

(17) Cao, F. F.; Deng, J. W.; Xin, S.; Ji, H. X.; Schmidt, O. G.; Wan, L. J.; Guo, Y. G. Cu-Si Nanocable Arrays as High-rate Anode Materials for Lithium-Ion Batteries. Adv. Mater. 2011, 23, 4415-20. 
(18) Epur, R.; Ramanathan, M.; Beck, F. R.; Manivannan, A.; Kumta, P. N. Electrodeposition of Amorphous Silicon Anode for Lithium Ion Batteries. Mater. Sci. Eng., B 2012, 177, 1157-1162.

(19) Abel, P. R.; Lin, Y.-M.; Celio, H.; Heller, A.; Mullins, C. B. Improving the Stability of Nanostructured Silicon Thin Film LithiumIon Battery Anodes through Their Controlled Oxidation. ACS Nano 2012, 6, 2506-2516.

(20) Wang, J. W.; He, Y.; Fan, F.; Liu, X. H.; Xia, S.; Liu, Y.; Harris, C. T.; Li, H.; Huang, J. Y.; Mao, S. X.; Zhu, T. Two-Phase Electrochemical Lithiation in Amorphous Silicon. Nano Lett. 2013, 13, 709-715.

(21) McDowell, M. T.; Lee, S. W.; Harris, J. T.; Korgel, B. A.; Wang, C.; Nix, W. D.; Cui, Y. In Situ TEM of Two-Phase Lithiation of Amorphous Silicon Nanospheres. Nano Lett. 2013, 13, 758-764.

(22) Choi, N.-S.; Yew, K. H.; Lee, K. Y.; Sung, M.; Kim, H.; Kim, S.S. Effect of Fluoroethylene Carbonate Additive on Interfacial Properties of Silicon Thin-film Electrode. J. Power Sources 2006, 161, 1254-1259.

(23) Etacheri, V.; Haik, O.; Goffer, Y.; Roberts, G. A.; Stefan, I. C.; Fasching, R.; Aurbach, D. Effect of Fluoroethylene Carbonate (FEC) on the Performance and Surface Chemistry of Si-Nanowire Li-Ion Battery Anodes. Langmuir 2011, 28, 965-976.

(24) Mahmood, N.; Zhang, C.; Liu, F.; Zhu, J.; Hou, Y. Hybrid of Co3Sn2@Co Nanoparticles and Nitrogen-Doped Graphene as a Lithium Ion Battery Anode. ACS Nano 2013, 7, 10307-10318.

(25) Szczech, J. R.; Jin, S. Nanostructured Silicon for High Capacity Lithium Battery Anodes. Energy Environ. Sci. 2011, 4, 56-72.

(26) Raistrick, I. D.; Franceschetti, D. R.; Macdonald, J. R. In Impedance Spectroscopy: Theory, Experiment, and Applications; Barsoukov, E., Macdonald, J. R., Eds.; Wiley: Hoboken, NJ, 2005; Chapter 2, pp 27-80.

(27) Goodenough, J. B.; Kim, Y. Challenges for Rechargeable Li Batteries. Chem. Mater. 2010, 22, 587-603.

(28) Ruffo, R.; Hong, S. S.; Chan, C. K.; Huggins, R. A.; Cui, Y. Impedance Analysis of Silicon Nanowire Lithium Ion Battery Anodes. J. Phys. Chem. C 2009, 113, 11390-11398.

(29) Zhang, H.; Yu, X.; Braun, P. V. Three-Dimensional Bicontinuous Ultrafast-Charge and Discharge Bulk Battery Electrodes. Nat. Nanotechnol. 2011, 6, 277-81.

(30) Ho, C.; Raistrick, I.; Huggins, R. Application of A-C Techniques to the Study of Lithium Diffusion in Tungsten Trioxide Thin Films. J. Electrochem. Soc. 1980, 127, 343-350.

(31) Sides, C. R.; Li, N.; Patrissi, C. J.; Scrosati, B.; Martin, C. R. Nanoscale Materials for Lithium-Ion Batteries. MRS Bull. 2002, 27, 604-607.

(32) Chockla, A. M.; Harris, J. T.; Akhavan, V. A.; Bogart, T. D.; Holmberg, V. C.; Steinhagen, C.; Mullins, C. B.; Stevenson, K. J.; Korgel, B. A. Silicon Nanowire Fabric as a Lithium Ion Battery Electrode Material. J. Am. Chem. Soc. 2011, 133, 20914-20921.

(33) Xia, F.; Kim, S. B.; Cheng, H.; Lee, J. M.; Song, T.; Huang, Y.; Rogers, J. A.; Paik, U.; Park, W. I. Facile Synthesis of Free-Standing Silicon Membranes with Three-Dimensional Nanoarchitecture for Anodes of Lithium Ion Batteries. Nano Lett. 2013, 13, 3340-3346.

(34) Rogach, A. L.; Kotov, N. A.; Koktysh, D. S.; Ostrander, J. W.; Ragoisha, G. A. Electrophoretic Deposition of Latex-Based 3D Colloidal Photonic Crystals: A Technique for Rapid Production of High-Quality Opals. Chem. Mater. 2000, 12, 2721-2726.

(35) Choi, J. W.; McDonough, J.; Jeong, S.; Yoo, J. S.; Chan, C. K.; Cui, Y. Stepwise Nanopore Evolution in One-Dimensional Nanostructures. Nano Lett. 2010, 10, 1409-1413. 